\title{
A estabilidade de bancarios e co- merciarios no emprego, em face da constituição
}

\author{
Dr. Waldemar Ferreira
}

1. Resulta o contrato de preposição mercantil ou de emprego no comercio da confluencia do de locação de serviços com o de mandato, em face do disposto nos arts. 74 a 86 do codigo comercial quanto aos feitores, guarda-livros e caixeiros.

Exigiu ele, primeiramente, a nomeação por escrito ou seja o titulo de investidura do preposto ou empregado e lhe impôs a obrigação de inscrevê-lo no registro competente, antes de entrar no exercicio do seu emprego. Perderia o omitente desta formalidade as vantagens atribuidas aos de sua classe. Caiu ela, no entanto, em desuso e, afinal, passados muitos anos, o decr. n. ${ }^{\circ}$ 5.511, de 13 de novembro de 1928 , tornou-a desnecessaria.

Não diminuiu isso a importancia do contrato. Nem o desfigurou. Aumentou-lhe, pelo contrario, a eficiencia, em relação ao preposto, que passou a fruir as vantagens legais mesmo sem titulo de nomeação escrito e regularmente inscrito.

2. Do simples fáto de estar o empregado a serviço do patrão advem para este graves responsabilidades pelos atos 
daquele. $\mathbf{O}$ empregado não é apenas auxiliar ou colaborador dele, senão tambem seu representante. Preposto é ele por colocar-se no lugar do patrão, fazendo-lhe as vêses, pra-ticando atos e contratos que somente por ele deveriam ser ajustados e executados. Daí veiu o principio, cardial no assunto, que o art. 75 recolheu: os preponentes respondem pelos atos dos feitores, guarda-livros e caixeiros, ou outros quaisquer prepostos,

a) praticados dentro das casas ou estabelecimentos comerciais;

b) relativos ao giro ou ramo do seu negocio.

Afastou, para terceiros, a necessidade de entrar na indagação da qualidade dos prepostos ou de seus poderes, ao tratar com eles dentro da loja, armazem, casa ou estabelecimento. Tornou-os presumidos. Fê-lo, porém, acrescentando só ficarem obrigados os preponentes por atos praticados por eles, fóra das casas comerciais, se se achassem autorizados pela fórma determinada no art. 74, isto é, por escrito. Quem, fóra de um estabelecimento comercial, se apresenta na qualidade de preposto do comerciante, está obrigado a comprová-la. Não poderá invocar a presunção legal o que não tiver a cautela de, em tais condições, contratar com o que preposto se inculque sem antes the verificar a qualidade alegada.

3. Assentou o codigo, com efeito, e foi no art. 78, a. responsabilidade do preposto ou agente auxiliar do comercio ao preponente por todo e qualquer dano que lhe causar por malversação, negligencia culpavel ou falta de exata e fiel execução de suas ordens e instruções, competindo até, contra ele, na primeira hipotese, ação criminal. De tal mo-do dispondo, imprimiu relevancia á função específica do preposto, subordinado á obrigação de cumprir, exata e fielmente, as instruções e ordens emanadas do preponente. Essa é, em verdade, a missão principal do preposto, quando. se propõe a prestar os seus serviços num estabelecimento 
comercial, em que a obediencia ás ordens superiores constitue a regra mestra da disciplina e da ordem.

Para a prestação de seus serviços, na maioria dos casos e no trato com terceiros, representa o preposto, necessariamente, ao preponente.

Mandou o codigo, no desenvolver do seu raciocinio, aplicar aos feitores as disposições relativas ao mandato. Referiu-se unicamente aos feitores, como, então, se chamavam os gerentes ou administradores de estabelecimento comercial. Viram alguns, nessa restricção do texto legislativo, um traço diferencial, capaz de servir de fundamento para a doutrina de somente os feitores representarem os patrões se, nos outros artigos, não tivesse ficado estabelecida, com todas as letras, a representação do patrão pelo empregado, dentro da casa comercial, para a pratica de quando por escrito autorizado.

Não se compreende, porém, a representação sem o mandato. Nem se pode considerá-lo inexistente quando o preposto é obrigado a cumprir ordens e instruções, mandado que ele é pelo patrão e responsavel pelo dano que, no cumprimento do mandato, lhe causar.

4. Estabelece-se, consequentemente, entre patrão e empregado um contrato típico: o de preposição ou emprego comercial, para cuja estrutura concorrem os contratos de locação de serviços e de mandato (WALDEMAR FERREI$R A$, Curso de Direito Comercial, vol. 1, n. ${ }^{\circ} 124$, p. 312; Tratado de Direito Mercantil Brasileiro, vol. 1, p. 444).

5. Dả-se o contrato de mandato, nos termos do art. 140 do codigo, quando o comerciante confia a outrem a gestão de um ou mais negocios mercantís, obrando o mandatario e obrigando-se em nome do mandante. Para a sua celebração é indispensavel, portanto, um elemento primacial cuja ausencia o aniquila e dissolve - a confiança. Desaparecendo ela, desaparece o mandato, tanto que o queira o mandante, revogando-o. Permite-lho, expressa- 


\section{$-75-$}

mente, o art. 157 do codigo. Acaba o mandato pela sua revogação, por parte do mandante.

Será assim no contrato de preposição mercantil? Póde qualquer das partes contratantes revogá-lo quando seja do seu aprazimento?

6. Não se achando acordado o prazo do ajuste celebrado entre o preponente e os seus prepostos, preceitúa o art. 81 do codigo, qualquer dos contraentes poderá dá-lo por acabado, avisando o outro da sua resolução com um mês de antecipação.

Nesse caso, acentuou o texto, quando o preponente tiver a iniciativa de dar o contrato por acabado, não será obrigado a conservar o preposto no seu serviço. Terá ele, porém, direito ao salario correspondente a esse mês.

Seguro sempre na sua doutrina, não compreendeu o codigo possa o patrão conservar o empregado, que lhe haja desmerecido a confiança. Conferiu-lhe, por isso, o direito de despedí-lo, mesmo sem justificação de motivos. Basta, nessa materia de extrema delicadeza, a simples suspeita para justificar a despedida. Alegá-la será ofender a dignidade do empregado, merecedora do maior respeito, tanto quanto a do patrão. Para evitar situação desse porte, assegurou a este a lei o direito á ruptura do contrato; mas igual direito reconheceu ao empregado, em identidade de situação.

Mas isto, note-se bem, quando não acordado o prazo do ajuste. Para a hipotese contrária, a da existencia de um termo estipulado, prescreveu o art. 82 do codigo não poder nenhuma das partes desligar-se da convenção arbitrariamente, sob pena de resarcir á outra os prejuizos que lhe causar.

Julgou o codigo, lançado tal principio, arbitraria a inobservancia da convenção por parte do preposto, quando não fundada em injuria feita pelo preponente á seguridade, honra ou interesses seus ou de sua familia; e quanto ao preponente, viu causas suficientes para a despedida do preposto na injuria por este a ele feita a sua seguridade, honra ou in- 
teresses seus ou de sua familia. Na incapacidade do preposto para o desempenho dos deveres e obrigações a que se sujeitou. No ato de fraude ou de abuso de confiança, por cle praticado. Na negociação a que ele se dedique por conta propria ou alheia, sem permissão do preponente.

A estabilidade do empregado durante todo o tempo do seu contrato ficou plenamente garantida, do ponto de vista patrimonial. Não assim, porém, quanto á sua conservação no emprego, em vista de sempre poder ser ele afastado: uma estabilidade instavel por depender da subsistencia da confiança. Como admitir o patrão no seu serviço empregado de cuja lealdade desconfie? Pois não é a desconfiança a perda da confiança? Nenhum estabelecimento é capaz de prosperar ou de manter-se no mesmo grau de prosperidade num ambiente de incertezas e de temores, de suspeitas e de sobresaltos.

Despedido, fica o preposto isento de prestar serviços, mas não destituido do direito de perceber os ordenados cuntratados, durante todo o tempo do ajuste, se injustamente despedido.

7. Mudou de diretrizes a recentissima legislação social brasileira, preocupada em reconhecer e assegurar o direito dos empregados no comercio - os comerciarios, como os chamou. Pretendeu estabilizá-los no seu emprego e impedir a redução dos seus ordenados. Como esse intuito o decr. n. 24.273 , de 22 de maio de 1934, permitiu a demissão ou a redução de vencimentos dos empregados e operarios que contarem mais de dez anos de serviços na mesma casa comercial, somente por motivo de falta grave, desobediencia, indisciplina ou circunstancia de força maior, devidamente comprovado. Regulamentando aquele decreto, o de $\mathrm{n}$. 183, de 26 de dezembro de 1934, em capitulo especial, lhe desmanchou a materia, desenvolvendo-a em inumeros artigos e, até, inovando-a.

Entrou a lei, em tais condições, na essencia do contrato de preposição mercantil, procurando manter o empregado no 
seu posto, a serviço do estabelecimento, mesmo em caso de manifesta incompatibilidade entre ele e o patrão. Reconheceu-lhe, observadas certas condições, o direito ao emprego, estavelmente, dando-lhe, a bem dizer, duração vitalicia.

8. Logo depois, outro decreto, o de n. 24.615, de 9 de julho de 1934, visando uma classe de prepostos ou empregados no comercio, os bancarios, lhes reconheceu e assegurou, particularmente, os direitos, já então proclamados.

$\mathrm{E}$ assim dipôs, no art. 15:

"Ao empregado em banco ou casa bancaria é assegurado o direito de efetividade, desde que conte dois ou mais anos de serviços prestados ao mesmo estabelecimento, e, salvo caso de falencia ou extinção do estabelecimento, só poderá ser demitido em virtude de falta grave, regularmente apurada em inquerito administrativo, de cuja abertura terá notificação afim de ser ouvido pessoalmente, com ou sem assistencia de seu advogado ou do sindicato da classe a que pertencer".

Manifestou-se uma variante técnica, com assegurar-se ao empregado em banco ou casa bancaria o "direito de efetividade"; mas, e no primeiro paragrafo ficou expresso, embora subordinada a demissão ao resultado do inquerito, e autorização do Conselho Nacional do Trabalho, se deixou bem claro que "o empregado acusado de falta grave poderá ser suspenso do serviço". E o art. 16 considerou falta grave:

a) qualquer ato de improbidade, que torne o empregado incompativel com o serviço do estabelecimento;

b) embriaguez habitual ou em serviço;

c) mau procedimento, ou desidia habitual, no desempenho das respetivas funções;

d) violação de segredo de que, por força do cargo, o empregado esteja de posse;

e) atos reiterados de indisciplina ou ato grave de insubordinação; 
f) abandono do serviço, sem causa justificada, por prazo superior a quinze dias;

g) atos lesivos da honra e boa fama praticados no serviço contra qualquer pessoa ou ofensas físicas nas mesmas condições, salvo em caso de legitima defesa, propria ou de outrem;

h) pratica constante de jogos de azar.

Acrescentou-se, no paragrafo segundo do art. 15:

"No caso de reconhecer o Conselho Nacional do Trabalho a inexistencia de falta grave do empregado, fica o estabelecimento obrigado a readimití-lo ao serviço e a pagar-lhe as remunerações a que teria direito no periodo da suspensão".

9. Estabeleceu-se, sem duvida, norma desconcertante da ordem contratual e da ordem disciplinar dos estabelecimentos comerciais. Quando comerciantes se virem obrigados, pela força, a admitir ou readmitir empregado, contra a sua vontade e com que se hajam, justa ou injustamente, incompatibilizado, terão perdido a necessaria autoridade moral para a eficiente administração de seus negocios. Sempre terão, no seu organismo, uma peça fraca a quebrarlhe o ritimo.

Que, no caso da despedida injusta, fiquem os comerciantes na obrigação de indenizar ao empregado despedido os danos causados, compreende-se; mas que, além disso, fiquem na obrigação de os readmitir nos seus estabelecimentos, isso é demasia inadmissivel em face dos principios juridicos que regem a materia.

10. A Constituição, porém, cortou a anomalia.

A legislação do trabalho observará, na conformidade do disposto no seu art. 121, $\S 1$, g, além de outros preceitos, que colimem melhorar as condições do trabalhador, os nele men- 
cionados, entre os quais o da "indenização ao trabalhador dispensado sem justa causa".

Póde sempre o patrão, mercê desse dispositivo constitucional, despedir o seu empregado ou preposto mercantil como trabalhador, que é: para o efeito do art. 121 da Constituição, no seu paragrafo segundo está escrito, não ha distinção entre o trabalho manual e o trabalho intelectual ou técnico, nem entre os profissionais respetivos. Se a despedida fôr por causa justa, liberto ficará o patrão de qualquer obrigação para com o empregado; se, porém, fôr por causa injustificada, escravo ficará ele de indenizar ao empregado dos prejuizos, que lhe causar, e apurados fôrem nos termos da lei.

11. Instaurado o regime constitucional, tratou o poder legislativo de, por lei ordinaria, regulamentar o dispositivo do art. 121, § 1, g, da Constituição; e, de fato, a lei n..$^{\circ} 62$, de 5 de Junho de 1935, assegurou ao empregado da industria ou do comercio, não existindo prazo estipulado para a terminação do respetivo contrato de trabalho, e quando fôr despedido sem justa causa, o direito de haver do empregador uma indenização paga na base do maior ordenado, que tenha percebido na mesma emprêsa. Essa indenização será de um mês de ordenado por ano de serviço efetivo ou por ano e fração igual ou superior a seis meses. Antes de completar-se o primeiro ano nenhuma indenização será devida e exigida.

Tendo em atenção as varias modalidades de percepção e de pagamento de remuneração, em voga no comercio e na industria, a lei prescreveu que:

a) se pagamento do trabalho fôr por dia, vinte e cinco dias servirão de base para o calculo da indenização;

b) se por hora, apurar-se-á na base de duzentas horas por mês;

c) se mediante comissão, na base da total dos ultimos doze mêses de serviço, dividida por doze; 
d) se por tarefa ou serviço feito, na base da media do tempo costumeiramente gasto pelo interessado para a feitura do serviço, calculando-se o valor do que seria feito durante vinte e cinco dias.

Eis, pois, a indenização regulada, quanto ao criterio de sua medida ou importancia, quando o contrato de trabalho, na hipotese o de preposição ou emprego no comercio, se convencionou-a sem clausula determinatoria do prazo de sua duração.

12. Havendo termo estipulado, refere o art. 7 da lei $n$. 62, de 5 de junho de 1935, nenhuma das partes poderá desligar-se do contrato, sob pena de indenizar a outra dos prejuizos que desse fato lhe resultarem.

Reproduziu o texto, quasi com as mesmas palavras, o preceito do art. 82 do codigo de comercio. Restaurando-o, rompeu - seguindo a trilha da Constituição - com o preceito instituidor da estabilidade dos empregados no comercio e na industria, posto em letra de fôrma pela legislação ditatorial. Ficou ela a depender de factores de ordem moral e, sobretudo, da conveniencia do patrão no conservar o empregado no seu serviço.

No regime em vigor não existe o direito do trabalhador de permanecer no emprego contra a vontade do patrão: assiste a este, por expresso na Constituição, o direito de despedi-lo sempre que isso se lhe tornar necessario e ao empregado o de ser indenizado, quando a despedida não se fizer justificadamente.

Não se argumente em prol da tese contraria com o disposto no art. 10 da lei n. 62 de 5 de junho de 1935:

“Os empregados que ainda não gozarem da estabilidade que as leis sobre institutos de aposentadorias e pensões têm creado, desde que contem dez anos de serviço efetivo no mesmo estabelecimnto, nos termos desta lei, só poderão ser demitidos por motivos devidamente comprovados de falta grave, desobediencia, indisciplina ou causa de força maior, nos termos do art. 5". 
Considera este artigo causas justas para a despedida além da suspensão do emprego ou cargo, por motivo de economia aconselhada pelas condições economicas e financeiras do empregador, determinada pela diminuição de negocios ou restrição da atividade comercial e comprovada por providencia de ordem geral, que atinja a todos os empregados e na mesma proporção dos vencimentos de cada um; pelo fechamento de um estabelecimento ou filial, em relação aos empregados destes; ou, ainda, pela suspensão de um determinado ramo de negocio - as seguintes:

a) qualquer ato de improbidade ou incontinencia de conduta, que torne o empregado incompativel com o serviço;

b) negociação habitual por conta propria ou alheia, sem permissão do empregador;

c) mau procedimento ou ato de desidia no desempenho das respetivas funções;

d) embriaguez habitual ou em serviço;

e) violação de segredo de que o empregado tenha conhecimento;

f) ato de indisciplina ou insubordinação;

g) abandono de serviço sem causa justificada;

h) ato lesivo da honra e boa fama praticado no serviço contra qualquer pessôa, ou ofensa físicas nas mesmas condições, salvo em caso de legitima defesa, propria ou de outrem;

i) pratica constante de jogos de azar;

j) força maior que impossibilite o empregador de manter o contrato de trabalho.

Não se argumente com tal dispositivo legal, sem força para revogar o do art. 121, § 1, g, da Constituição, segundo o qual a legislação do trabalho terá, necessariamente, de observar o preceito da "indenização ao trabalhador dispensado sem justa causa". Se a lei ordinaria tem de observar tal preceito, é porque a Constituição reconhece ao empregador o direito de despedir, a qualquer tempo, o empregado, su- 
jeitando-o á obrigação de indenizá-lo dos prejuizos, que lhe causar, quando dispensado sem justa causa.

Quer isso dizer, ou o texto constitucional não tem sentido, que não é possivel manter-se um empregado no serviço do empregador, contra a vontade deste: não assiste áquele o direito de conservar-se, a todo o transe, no emprego, senão o de haver a indenização, que a Constituição lhe assegura, quando dele afastado sem justa causa, ainda que conte mais de dez anos de serviço efetivo no mesmo estabelecimento (1).

13. Tratou a lei $\mathrm{n} .62$, de 5 de junho de 1935 , de assegurar ao empregado da industria ou do comercio, despedido sem justa causa, o direito de haver do empregador a indenização devida. E estabeleceu os diferentes criterios para determinar-lhe a importancia, quando inexistir prazo estipulado para a terminação do respetivo contrato de trabalho.

1) Interessante é, sem duvida, o caso sobre que teve de manifestar-se, no agravo de petição n. 6.525, a Côrte Suprema.

Vale a pena trasladá-lo para estas paginas:

\section{"RELATORIO}

O Sr. Ministro Laudo de Camargo - A Fazenda Nacional, pelá secção de Belo Horizonte, propôs um executivo fiscal contra o Banco de Credito Real de Juiz de Fóra, para haver a quantia de 1:000\$000, proveniente de multa imposta pelo Ministerio do Trabalho, maximo previsto pelo art. 35 do decreto $n$. 24.694, de 12 de Julho de 1934 . cometido.

Em embargos, disse o executado que nenhuma infração havia

Transferiu da matriz para uma das suas agencias o funcionario Hercules Magaldi mas posteriormente deixou sem efeito a transferencia, para coloca-lo em disponibilidade, com a percepção de todos os vencimentos enquanto desempenhasse funções em um sindicato de que se tornara membro.

E assim procedeu para atender ao regimento do Banco, aprovado pelo Governo e segundo o qual o empregado deve inteira dedicação ás funções.

O juiz não acolheu a defesa.

Entendeu que o Banco agira mal, fazendo transferir o empregado, pelo só fato de fazer parte de um sindicato e mal procedera ainda o colocando fóra das funções pelo mesmo motivo.

Daí o julgar procedente o executivo, pelo que a parte condenada veiu a agravar. 
Num ponto, entretanto, foi ela omissa: não disse palavra sobre a importancia da indenização devida quando existente a estipulação do prazo duracional do contrato. Como, em tal caso, deve ser calculada? Qual o criterio a seguir para essa apuração?

14. Nenhum juiz deixará de sentenciar por motivo de omissão na lei. Deverá, em tal caso e nos termos do art. 113, n. 37, da Constituição, decidir por analogia, pelos principios gerais de direito ou por equidade.

Fê-lo em tempo e fórma.

Este o parecer da Procuradoria Geral. (Lề a fls. 39) :

"Foi imposta multa por autoridade competente e por infração de lei sobre o trabalho. O caso é liquido e bem fundamentado pelo $\mathrm{Dr}$. Juiz Federal; pelo que não parece merecedor de provimento o agravo".

\section{VOTO}

O Sr. Ministro Laudo de Camargo (Relator) - Não deixa de ser interessante a hipotese em discussão.

o Banco de Credito Real de Minas Gerais, com séde em Juiz de Fóra, fez transferir, para a agencia de Lavras, um seu empregado, que se achava sindicalizado.

Intimado oficialmente para reconsiderar o ato, ele o fez, mas para deixar em disponibilidade provisoria o mesmo, que passou a perceber os vencimentos integrais, enquanto desempenhasse funções no Sindicato.

Assim procedeu, segundo afirmou, para observar o disposto nos seus estatutos, aprovados pelo Governo Federal, que dispõem: “os empregados devem devotar-se inteira e exclusivamente ao serviço do Banco, não podendo aceitar outro qualquer trabalho ou comissão, salvo com prévio consentimento da "Diretoria".

O seu procedimento, visou, portanto, conciliar interesses proprios com os do empregado, sem qualquer ofensa á lei.

Estará certo esse proceder?

Não tenho duvidas em afirma-lo.

A lei procurou amparar os empregados dando-lhes estabilidade no cargo e impedindo a ação compressora dos empregados.

Transcrevo o texto legal: “E' vedado aos patrões ou empresas despedir, suspender ou rebaixar de categoria, de salario ou de ordenado o empregado com a intenção de obstar que se associe ou procure formar associação para fins sindicais ou pelo fato de já se ter associado a sindicato".

Mas em nenhuma das hipoteses previstas seria possivel incluir a dos autos. 
Se se considerar, ademais, ter o art. 121 do codigo do comercio exarado o principio de aplicarem-se aos contratos comerciais as regras e disposições do direito civil para os contratos em geral, neste se deverá procurar a legislação subsidiaria capaz de servir de paradigma para a solução da controversia.

Ora, disciplinando a locação de serviços o codigo civil consignou, no art. 1.288, este preceito:

"O locatario que, sem justa causa, despedir o locador, será obrigado a pagar-lhe por inteiro a retribuição vencida, e por metade a que lhe tocaria de então ao termo legal do contrato".

O Banco não despediu o empregado, porquanto o continúa sendo; não o suspendeu, suspensão considerada pena; não o rebaixou de categoria, porque continúa usufruindo os mesmos proventos do cargo. que isto?

E' certo que ficou com uma interrupção nas funções. Mas por

Justamente para que o empregado desempenhasse as funções no Sindicato e emquanto elas perdurassem, não prejudicando deste modo os serviços do Banco.

Este, e nunca aquele, é que seria prejudicado, por ter de pagar os vencimentos integrais a quem não iria atender aos seus interesses.

Vê-se assim que a suspensão condenada pela lei não é tão só a que implica em pena e com a qual se prejudica moral e economicamente o empregado. animou.

E' preciso atender-se ao preceito legal, pelo espirito que o

Já se chegou a avançar que o empregado, mal despedido, terá de forçosamente voltar a desempenhar as mesmas funcões, no mesmo lugar e ás mesmas horas, queira-o ou não o patrão.

Tal, porém, não acontece, pois a legislação não compeliu em absoluto ao empregador a ter como empregado aquele a quem recusa essa qualidade.

Daí este parecer: "Não ha legislação no mundo que obrigue um patrão a ter contra a sua vontade e a seu serviço, um empregado" (Diario Oficial de 27 de Dezembro de 1934).

Por isso, tudo se resolverá no terreno puramente economico, com a indenização devida.

Hoje não mais se poderá discutir a respeito, quando é a propria Constituição que, pelo art. $121, \S 10^{\circ}$, letra $e$, dispõe que a legislação do trabalho observará, como preceito - "a indenização ao trabalhador dispensado sem justa causa".

Importa em dizer que, indenizando, a propria dispensa não está sujeita a restrição alguma. E esta indenização está prevista em lei. 
Eis uma disposição, concernente a caso analogo, a oferecer o criterio para o calculo da indenização devida ao empregado no comercio ou na industria, que fôr dispensado do serviço, sem causa justificada, antes de terminar-se o prazo de duração estipulado no seu contrato de trabalho.

15. Postos estes principios, expressos ou decorrentes das leis em vigor, tanto da constitucional, quanto das ordinarias, não ha senão tirar as conclusões que se seguem.

16. Assegurou, com ef eito, o art. 15 do decr. n. 24.615, de 9 de julho de 1934, ao empregado em banco ou casa ban-

Em suma: deixando em disponibilidade o empregado, com o pagamento de todos os seus vencimentos, enquanto estiver desempenhando funções no Sindicato e com o direito de reassumir o seu cargo, quando essas funções cessarem, o Banco não infringiu a lei, pelo que o seu ato não é passivel de qualquer censura.

Assim, dou provimento ao agravo para, reformando a decisão agravada, julgar improcedente o executivo, por ser nenhuma a infração e, consequentemente, nenhuma a cobrança.

\section{ACÓRDÃO}

Vistos, relatados e discutidos estes autos de agravo n. 6.525, de Minas Gerais, em que são agravante o Banco de Credito Real de Minas Gerais e agravada a Fazenda Nacional.

Esta cobrou daquele a importancia de reis 1:000\$000, por infração do art. 35 do decreto n. 24.694 de 12 de Julho de 1934 .

Mas cobrou mal, pois nenhuma infração foi cometida, uma vez que o Banco agravante, regularizando a situação interna do estabelecimento, deixou em disponibilidade e com todos os proventos pecuniarios, a um seu empregado, enquanto perdurassem as suas funções no sindicato a que pertence.

Esse ato se traduziu no exercicio legitimo de um direito e como tal deve ser encarado, pois não houve dispensa, tampouco suspensão condenada e muito menos rebaixamento de cargo.

Assim, acórdão em Côrte Suprema dar provimento ao agravo para, reformando a decisão agravada, julgar improcedente o executivo e insubsistente a penhora, tudo nos termos dos votos proferidos e constantes das notas taquigráficas juntas, pagas pela agravada as custas.

Rio de Janeiro, 8 de Janeiro de 1936. - E. Lins, Presidente. - Laudo de Camargo, Relator". 
caria o direito de efetividade, desde que contasse dois ou mais anos de serviços prestados ao mesmo estabelecimento. Assegurando-lhe tal direito, houve por bem o texto acrescentar que, salvo o caso de falencia ou de extinção do estabelecimento, o empregado só poderia ser demitido em virtude de falta grave, regularmente apurada em inquerito administrativo, de cuja abertura teria notificação, afim de ser ouvido pessoalmente, com ou sem assistencia de seu advogado ou do representante do sindicato da classe a que pertencesse.

Aquele decreto, nos termos do seu art. 32, entrou em vigor sessenta dias após sua publicação, ou seja em dias de setembro de 1934.

17. Dias depois dele publicado, em 16 de julho de 1934, foi promulgada e entrou em execução a Constituição da Republica, cujo art. 121, $\S 1$, g, determinou que a legislação do trabalho teria, forçosamente, de obedecer, entre outros preceitos, ao da "indenização ao trabalhador dispensado sem justa causa".

Não se póde, em bôa hermeneutica, admitir que, tendo a Constituição, em tal dispositivo, reconhecido o direito do empregado dispensado sem justa causa á indenização, não houvesse admitido a dispensa nessas condições. Seria um contrasenso aberrante. Admitindo-a, não deu como remedio á molestia a reintegração forçada do empregado no seu emprego, mas a indenização. Afastou, portanto, e iniludivelmente, o conceito da estabilidade do empregado, de modo a somente poder ser ele afastado do seu emprego no caso de falta grave, reconhecida pelo Conselho Nacional do Trabalho.

18. Não padece duvida, portanto, que não chegou a entrar em vigor o dispositivo do art. 15 e seus paragrafos do decr. n. 24.615, de 9 de julho de 1934, por contrario ao preceituado no art. 121, $\S 1$, g, da Constituição. Acresce salientar que, quando ela entrou em vigor, vigorando ainda não estava aquele decreto e, ademais, que ainda não deu a 
lei ordinaria organização á Justiça do Trabalho, instituida pelo art. 122 da Constituição, para dirimir questões entre empregadores e empregados, regidas pela legislação social.

\section{I}

19. Refere-se a lei n. 62 , de 5 de junho de 1935 , indistintamente, a todos os empregados no comercio ou na industria, afim de regular a indenização, que lhes assiste, quando, ajustados sem contrato escrito ou em que não tenha sido estipulado o prazo de sua duração, sejam despedidos sem justa causa. Entre eles se incluem os bancarios, em especial e, em geral, os comerciarios. A nenhum compete, como se acaba de demonstrar, o direito ao emprego, como coisa sua, ao seu patrimonio incorporado e em cujo exercicio possa ser reintegrado. Assiste-lhes o direito de perceber a remuneração convencionada, enquanto neles permanecerem e, se despedidos injustamente, a uma indenização.

20. Se não existir prazo estipulado para a terminação do respetivo contrato de trabalho, calcular-se-á a indenização de acôrdo com os preceitos da lei n. 62 , de 5 de junho de 1935. Não se admitem, em face dela, distinções relativamente á especie de emprego e á condição do trabalhador, nem entre o trabalho manual, intelectual ou técnico e os profissionais respetivos.

Havendo termo estipulado, a indenização, por analogia, deverá ser apurada nos termos do art. 1.228 do codigo civil.

21. Alude o art. 13, § unico, da lei n. 62 , e convém por isso em destaque, á readmissão do empregado suspenso até final processo de investigação da falta grave, de que tenha sido acusado:

"Provada a inexistencia de falta grave, o empregado readmitido receberá integralmente os vencimentos e vantagens a que teria direito se não houvesse sido suspenso". 
Aplicar-se-á o dispositivo, evidentemente, se a readmissão se verificar. Bem poderá acontecer, e muitas veses acontecerá, venha o empregador a convencer-se da inteira inocencia do empregado. Quantos não terão sido, e não serão ainda, vitimas de campanhas malevolas e infamantes, urdidas nos bastidores dos proprios estabelecimentos comerciais ou industriais?

O empregado readmitido, mercê da sua rehabilitação, receberá integralmente os vencimentos e vantagens a que teria direito, se não houvesse sido suspenso.

A readmissão jamais se efetivará pela força: resolverse-á pela obrigação de indenizar.

\section{I I}

22. Podem, sem duvida, ser despedidos, a qualquer tempo, os empregados de bancos ou casas bancarias.

Justificada a causa da despedida - uma das enumeradas no art. 5 da lei n. 62 , de 5 de junho de 1935 - indenização alguma lhe será devida.

Injustificada a causa, a despedida acarretará para o banco ou casa bancaria a obrigação de indenizar.

\section{V}

23. O direito de efetividade no emprego, conferido pelo art. 15 do decr. n. 24.615, de 9 de julho de 1934, a todo empregado em banco ou casa bancaria, que contasse dois anos ou mais de serviços no mesmo estabelecimento, caberia, por certo, a quantos se achassem nessas condições no momento da entrada em vigor daquele decreto. Nem haveria como, na hipotese, falar em retroatividade da lei.

Sobre não ter entrado em vigor aquele dispositivo, em vista da demonstração neste parecer largamente desenvolvida, ẻ de não perder de vista, ainda, haver o art. 2 da lei 
n. 62 , de 5 de junho de 1935 , prescrito que, "antes de completo o primeiro ano, nenhuma indenização será exigida". Fez a lei ordinaria, no tempo, restrição que não está no texto constitucional, que assegura sempre a indenização ao trabalhador dispensado sem justa causa.

Rio de Janeiro, 10 de agosto de 1935. 